Open Journal of Gastroenterology and Hepatology
(ISSN:2637-4986)

\title{
Kayexalate or Kalimate crystals: are they the culprits or the bystanders?
}

\author{
Chen Fang Hsu, Swei H Tsung \\ Department of Pathology, St Mary Hospital, Loudong, Yilan, Taiwan
}

\section{ABSTRACT}

Sodium polystyrene sulfonate (Kayexalate) or its analog calcium polystyrene sulfonate (Kalimate) has long been used to treat hyperkalemia in patients with chronic kidney disease (CKD). Although the side effect was rare, there were many case reports in the literature. Its etiology remains unclear. Lillemoe et al., on five uremic patients who developed catastrophic colonic necrosis that was temporally associated with the use of Kayexalate in sorbitol, contributed to death in four of their patients. They further provided experimental evidence implicating sorbitol as the agent responsible for colonic necrosis in a rat model. In contrast to the results of aforementioned animal study, Ayoub et al., published another experimental study in rats, they demonstrated that sodium polystyrene sulfonate (SPS), not sorbitol, was the main culprit for colonic necrosis. Recently, we encountered three patients who had hyperkalemia and were on Kalimate in water. They underwent colonic and gastric biopsy because of developing gastrointestinal symptoms. Kalimate crystals were found in all biopsy specimen, admixed with inflammatory exudate, or standing along on the mucosa surface, without provoking inflammatory reaction. We reviewed the photographs in the published case reports, they were similar to ours. Therefore, we felt that those crystals were bystanders, not the culprits. We fell that SPS ion-exchange resins, if given in water, appears to be clinically effective and reasonably safe to treat hyperkalemia in patients with CKD.

Keywords: Kayexalate, kalimate, hyperkalemia, chronic kidney disease, side effect.
${ }^{*}$ Correspondence to Author:

Swei H. Tsung, M.D.

Department of Pathology, $160 \mathrm{~S}$ Chong Chun Rd, St Mary's Hospital Loudong, Yilan, Taiwan

Chen Fang Hsu, M.D.

Department of Pathology, $160 \mathrm{~S}$ Chong Chun Rd, St Mary's Hospital Loudong, Yilan, Taiwan

How to cite this article:

Chen Fang Hsu, Swei H Tsung. Kayexalate or Kalimate crystals: are they the culprits or the bystanders? .Open Journal of Gastroenterology and Hepatology, 2020, 3:28.

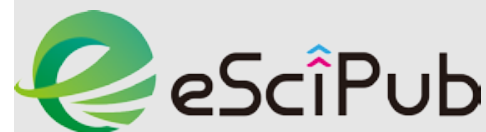

eSciPub LLC, Houston, TX USA. Website: https://escipub.com/ 
Sodium polystyrene sulfonate [Kayexalate] or its analog calcium polystyrene sulfonate [Kalimate] is an ion-exchange resin commonly used to treat hyperkalemia in patients with chronic kidney disease [CKD]. The first case report of colon necrosis in association with the use of sodium polystyrene [SPS] was presented by Arvanitakis et al. in 1973, even before FDA approved the use of SPS in 1975 [1]. Although the side effect was rare, there were many case reports appearing in the literature [2, 3]. The side effects included colorectal and small bowel necrosis, even with perforation, and hemorrhagic gastritis. Few cases required surgical resection, even fewer cases resulted in fatal outcome. Of interest was the report by Lillemoe et al., on five uremic patients who developed catastrophic colonic necrosis that was temporally associated with the use of Kayexalate in sorbitol and contributed to death in four of their five patients [4]. They further provided experimental evidence implicating sorbitol as the agent responsible for colonic necrosis in a rat model. The majority of reported complications were concomitant use of kayexlate with $70 \%$ sorbitol. In all of the reported cases, the authors demonstrated SPS crystals in conjunction with the necrotic lesions. In 2009, the US Food and Drug administration issued warning regarding concomitant use of SPS with $70 \%$ sorbitol. However, this warning did not apply to pre-mixed SPS in 33\% sorbitol. It became the only SPS resin available in many hospitals in US. Cases with adverse effects were still reported, despite the use of SPS in 33\% sorbitol formulation.
In 2015, Ayoub et al., published the second experimental study in rats concerning colon necrosis due to SPS with and without sorbitol [5]. In contrast to the result by Lillemoe et al. [4], their study showed that SPS, not sorbitol, was the main culprit for colon necrosis. However, the applicability of the animal model to human beings remains uncertain.

Recently, we encountered three patients with $C K D$, and were on kalimate in water for hyperkalemia. The clinical data of these three patients were summarized in table 1. In case 1 , the patient had blood drainage from NG tube. She underwent gastroscopy which showed severe ulceration [fig A1]. The biopsy was taken and the specimen displayed gastric ulcer with fragments of kalimate crystals [fig A2, A3]. In case 2 and 3 , the patients underwent colonoscopy because of bloody stool and anal bleeding respectively. In case 2 , the colonoscopy showed erythematous patches [fig B1], and biopsy report indicated non-specific colitis with kalimate crystals [fig B2, B3]. In case 3 , the colonoscopy showed a polyp [fig C1], and the biopsy tissue exhibited a tubular adenoma with kalimate crystals [fig C2, C3].In those three cases, the crystals were either standing along on the mucosa surface, or admixed with inflammatory exudate without provoking inflammatory reaction. We reviewed the photographs in the published case reports, they were similar to ours. We felt that those crystals were bystanders, not the culprits.

Scherr et al., showed SPS was effective when given with water, and recommended clinician 
should consider administering it in water, resins were "largely unproven and potentially especially in enema form [6]. In a systemic harmful”, especially when administered with review article by Harel et al., they identified 58 sorbitol, and clinicians should "exhaust other cases of possible gastrointestinal adverse alternative" [9]. Watson et al., felt these events associated with sodium polystyrene conclusions were immoderate [10].

sulfonate [SPS] use with and without In summary, we report our observation in three concomitant sorbitol-containing preparation [7]. Their review suggested that sorbitol might not be the contributing factor for the adverse event. A retrospective cohort study by Watson et al., indicated SPS-associated colonic necrosis risk was not significantly greater than the background rate of colonic necrosis [8]. Stern et cases and review the literature, and suggest that the crystals associated with the use of Kayexalate or Kalimate may be an incidental finding. We fell that SPS ion-exchange resins, if given with water, appear to be clinically effective and reasonably safe to treat hyperkalemia in patients with chronic kidney disease.

al., in an editorial review, concluded that SPS

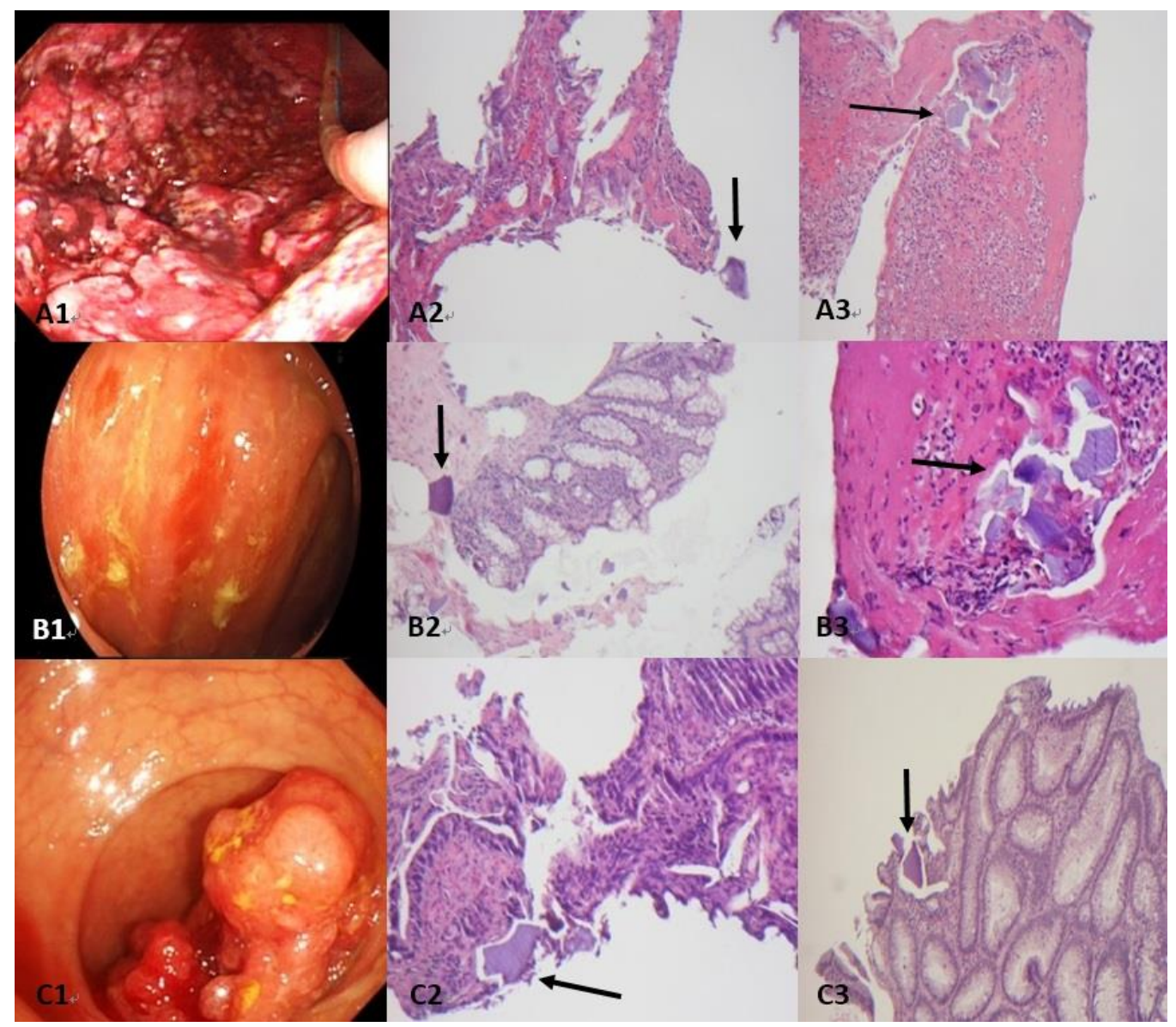

A1: Gastroscopy showing severe ulcer. A2: Kalimate crystal [arrow] attached to the mucosa. A3 Kalimate crystals [arrow] floating in ulcerated debri.B1: Colonoscopy showing red patches of the sigmoid colon. B2: Kalimate crystal [arrow] standing along in the submucosa. B3: Kalimate crystals [arrow] admixed with inflammatory exudate. C1: Colonoscopy showing a polyp in the sigmoid colon. C2 and C3: Kalimate crystals [arrow] coated on the tumor surface. 
Chen Fang Hsu and Swei H Tsung, OJGH, 2020:3:28

\begin{tabular}{|c|c|c|c|}
\hline & Case $1[\mathrm{~A}]$ & Case 2[B] & Case $3[\mathrm{C}]$ \\
\hline age[yr] & 55 & 68 & 74 \\
\hline Sex & female & male & Female \\
\hline \multirow[t]{7}{*}{ Commorbidities } & DM & HTN & Gouty arthritis \\
\hline & Anemia & Lung carcinoma & DM \\
\hline & HTN & CKD & CKD \\
\hline & CKD & Dyslipidemia & \\
\hline & $\mathrm{CHF}$ & Liver cirrhosis & \\
\hline & & Post-liver transplantation & \\
\hline & & DM, Anemia & \\
\hline Presenting complaints & $\begin{array}{l}\text { Blood drainage from NG } \\
\text { tube }\end{array}$ & Bloody stool & Anal bleeding \\
\hline Endoscopic impression & $\begin{array}{l}\text { Gastric ulcer with } \\
\text { bleeding at the body }\end{array}$ & $\begin{array}{l}\text { Erythematous patches at } \\
\text { sigmoid colon }\end{array}$ & $\begin{array}{l}\text { A big polyp with } \\
\text { bleeding }\end{array}$ \\
\hline Pathologic diagnosis & $\begin{array}{l}\text { Gastric ulcer with kalimate } \\
\text { crystal }\end{array}$ & $\begin{array}{l}\text { Chronic colitis with kalimate } \\
\text { crystal }\end{array}$ & $\begin{array}{l}\text { TA with high grade } \\
\text { dysplasia, kalimate } \\
\text { crystal }\end{array}$ \\
\hline Kalimate dose/rout & $\begin{array}{l}15 \mathrm{~g} \text { suspended in } 30-50 \\
\mathrm{cc} \text { water tid, by mouth }\end{array}$ & $\begin{array}{l}15 \mathrm{~g} \text { suspended in } 30-50 \mathrm{cc} \\
\text { water, tid, by mouth }\end{array}$ & $\begin{array}{l}15 \mathrm{~g} \text { suspended in } \\
30-50 \mathrm{cc} \text { water, tid } \\
\text { by mouth }\end{array}$ \\
\hline On renal dialysis & Yes & Yes & Yes \\
\hline \multirow[t]{2}{*}{ Abbreviation: } & Mellitus & HTN=Hypertension & nic Kidney Disease \\
\hline & e Heart Failure & $\mathrm{TA}=$ Tubular adeno & \\
\hline
\end{tabular}

\section{References:}

1. Arvanitakis C, Malek G, Uehling D, Morrissey JF. Colonic complication after renal transplantation. Gastroenterology 1973; 64;533-538.

2. Rashid A, Hamilton S: Necrosis of the gastrointestinal tract in uremic patients as a result of sodium polystyrene sulfonate [Kayexalate] in sorbitol: An underrecognized condition. Am J Surg
Pathol 1997;21: 50-69.

3. Abraham SC, Bhagavan BS, Lee LA, Rashid A, Wu TT: Upper gastrointestinal tract in patients receiving Kayxalate [ sodium polystyrene sulfonate] in sorbitol. Am J Surg Pathol 2001; 25:637-644.

4. Lillemoe KD, Romolo JL, Hamilton SR, Pennington LR, Burdick JF, William GM: Intestinal 
necrosis due to sodium polystyrene[Kayexalate]

in sorbitol enema: Clinical and experimental support for the hypothesis: Surgery 1987 101:267-272,

5. Ayoub I, Oh MS, Gupta R, McFarlane M, Baniska A, Salifu O. Colonic necrosis due to sodium polystyrene sulfonate with and without sorbitol: An experimental study in rats. PLOS ONE 10[9] : September 28 2015 e0137636.doi:10.1371/journal.pone.0137636

6. Scherr L, Ogden DA, Mead AW, Spritz N, Rubin LA. Management of hyperkalemia with a cationexchange resin. N Engl J Med 1961; 264:115-119.

7. Harel Z, Harel S, Shah PS, Wald R, Perl J, Bell CM. Gastrointestinal adverse events with sodium polystyrene sulfonate [Kayexalate] use: A systematic review. Am J of Med 2013;126: 263e9$264 \mathrm{e} 24$

8. Watson MA, Baker TP, Nguyen A, Sebastianelli ME, Stewart HL, Oliver DK, et al. Abbott KC, Yuan $\mathrm{CM}$ : Association of prescription of oral sodium polystyrene sulfonate with sorbitol in an inpatient setting with colonic necrosis: A retrospective cohort study. Am J Kidney Dis 2012; 60; 409-416.

9. Sterns RH, Rojas M, Bernstein P, Chennupati S: lon-Exchange resins for the treatment of hyperkalemia: Are they safe and effective? J Am Soc Nephrol 2010;21:733-735.

10. Watson M, Abbott KC, Yuan CM: Damned if you Do, Damned if you don't: Potassium binding resins in hyperkelamia: J Am Soc Nephrol 2010; 5:1723-1726,

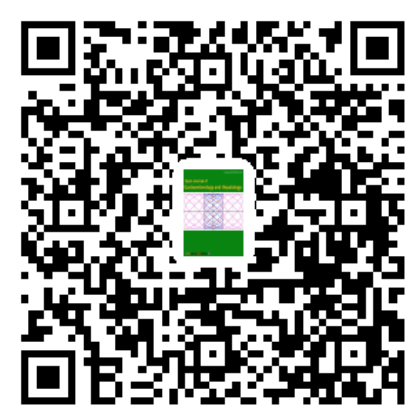

